\title{
EXPERIMENTAL DESIGN AND ECOLOGICAL REALISM
}

In a recent letter, Rose (1982) raised certain questions concerning a paper on crayfish communication by Itagaki and Thorp (1981) which concluded that individuals of Procambarus clarkii do not recognize the sex of conspecifics by detection of pheromones. Rose's (1982) comments and Thorp and Itagaki's reply (1982) were particularly interesting, since Itagaki and Thorp's (1981) conclusions were in contrast to earlier results demonstrating pheromone detection of conspecific sex by males in this species (Ameyaw-Akumfi and Hazlett, 1975).

I tend to agree with many of the points in Rose's letter. However, I wish to question one of his assumptions - that the experimental design of Itagaki and Thorp was appropriate. In testing crayfish for behavioral changes following exposure to "conditioned water," we (Ameyaw-Akumfi and Hazlett, 1975) utilized a nonflow (static) system, whereas Itagaki and Thorp (1981) used a flow-through system. Itagaki and Thorp argued that the flow-through system avoided possible contamination from the build-up of waste products. Their concern was at least partially based upon earlier results which indicated the production of stress pheromones in a related species, $P$. acutus (Thorp and Ammerman, 1978). Itagaki and Thorp (1981) agree that the specific differences in our respective results on $P$. clarkii may be methodological, but I wish to raise a general question of appropriateness of experimental procedures.

Thorp and Itagaki (1982) are correct in pointing out that as scientists we must do our best to falsify hypotheses and avoid playing advocacy science. But the ecology of the organisms we study can render some experimental designs questionable. For example, Procambarus clarkii, the red swamp crayfish, occurs in lentic waters and is almost never found in streams (see Spohrer et al., 1975). It is strongly associated with burrows. Given an organism that lives in "static systems," is it meaningful to test it in a flowing system? Surely if an aerial system of testing were judged to be methodologically cleaner, we would not consider it a realistic means of hypothesis falsification for aquatic animals. Crayfish such as Orconectes virilis live in burrows in both lotic and lentic environments and evidence of sex recognition by chemicals has been obtained by both static (Ameyaw-Akumfi, 1976) and flow-through (Tierney and Dunham, 1982) methods. 
Dunham (1978) and others have outlined methodological points which should be taken into account by those testing for pheromonal communication, a number of them clearly improvements on the methods we have used. However, I would stress that ecological realism must also be considered in our experimental design, if our attempts to falsify hypotheses are to increase our understanding of biology.

\author{
Brian A. Hazlett \\ Division of Biological Sciences \\ University of Michigan \\ Ann Arbor, Michigan 48105
}

\title{
REFERENCES
}

AMEYAW-AKUMFI, C.E. 1976. Some aspects of breeding biology of crayfish. PhD dissertation. University of Michigan, Ann Arbor. 252 pp.

AmeYaw-Akumfi, C. and Hazlett, B.A. 1975. Sex recognition in the crayfish Procambarus clarkii. Science 190:1225-1226.

Dunham, P.J. 1978. Sex pheromones in Crustacea. Biol. Rev. 53:555-583.

ITAGAKI, H., and ThORP, J.H. 1981. Laboratory experiments to determine if crayfish can communicate chemically in a flow-through system. J. Chem. Ecol. 7:115-126.

ROSE, R.D. 1982. On the nature of chemical communication by crayfish in a laboratory controlled flow-through system. J. Chem. Ecol. 8:1065-107I.

Spohrer, M.L., Williams, J.L., and Avault, J.W., JR. 1975. A selected bibliography of the red swamp crayfish, Procambarus clarkii (Girard) and the white river crayfish, Procambarus acutus acutus (Girard), pp. 637-661, in J.W. Avault, Jr. (ed.). Freshwater Crayfish. LSU Press, Baton Rouge.

ThorP, J.H., and Ammerman, K.S. 1978. Chemical communication and agonism in the erayfish Procambarus acutus acutus. Am. Midl. Nat. 100:471-474.

THORP, J.H., and ITAGAKI, H. 1982. Verification versus falsification of existing theory: Analysis of possible chemical communication in crayfish. J. Chem. Ecol. 8:1073-1077.

TierneY, A.J., and Dunham, D.W. 1982. Chemical communication in the reproductive isolation of the crayfishes Orconectes propinquus and Orconectes virilis (Decapoda, Cambaridae). $J$. Crust. Biol. 2:544-548. 